GA-A24039

\title{
FEEDBACK CONTROL OF \\ THE DIII-D ECH SYSTEM
}

\author{
by \\ J. LOHR, J.R. FERRON, Y.A. GORELOV, K. KAJIWARA, \\ D. PONCE, and M.R.WADE
}




\section{DISCLAIMER}

This report was prepared as an account of work sponsored by an agency of the United States Government. Neither the United States Government nor any agency thereof, nor any of their employees, makes any warranty, express or implied, or assumes any legal liability or responsibility for the accuracy, completeness, or usefulness of any information, apparatus, product, or process disclosed, or represents that its use would not infringe privately owned rights. Reference herein to any specific commercial product, process, or service by trade name, trademark, manufacturer, or otherwise, does not necessarily constitute or imply its endorsement, recommendation, or favoring by the United States Government or any agency thereof. The views and opinions of authors expressed herein do not necessarily state or reflect those of the United States Government or any agency thereof. 


\title{
FEEDBACK CONTROL OF THE DIII-D ECH SYSTEM
}

\author{
by \\ J. LOHR, J.R. FERRON, Y.A. GORELOV, K. KAJIWARA, ${ }^{*}$ \\ D. PONCE, and M.R.WADE ${ }^{\dagger}$
}

This is a preprint of an invited paper to be presented at the Twenty-Seventh International Conference on Infrared and Millimeter Waves, September 22-26, 2002, San Diego, California, and to be published in the Proceedings.

"Oak Ridge Instiutute for Science Education, Oak Ridge, Tennessee.

†Oak Ridge National Laboratory, Oak Ridge, Tennessee.

\section{Work supported by \\ the U.S. Department of Energy under Contract Nos. DE-AC03-99ER54463, DE-AC05-000R00033, and DE-AC05-000R22725}

\section{GENERAL ATOMICS PROJECT 30033 AUGUST 2002}




\title{
Feedback Control of the DIII-D ECH System
}

\author{
J. Lohr, J.R. Ferron, Y.A. Gorelov, K. Kajiwara, ${ }^{a}$ D. Ponce, M.R. Wadeb \\ General Atomics, P.O. Box 85608, San Diego, California 92186-5608 \\ ${ }^{a}$ Oak Ridge Institute for Science Education, Oak Ridge, Tennessee. \\ ${ }^{b}$ Oak Ridge National Laboratory, Oak Ridge, Tennessee.
}

Abstract. The output power of the DIII-D gyrotron complex has been modulated by the plasma control system using feedback on the difference between a desired electron temperature and the ECE measurement. Operation was stable and permitted control of the flux penetration during initiation of the discharge.

\section{INTRODUCTION}

One of the main advantages of electron cyclotron waves for improvement of tokamak performance is that the localized absorption permits specific locations in the plasma, characterized by values of normalized flux, $\rho$, to be targeted for the heating and or current drive. Typically, the power absorption is localized poloidally, toroidally and radially to within a range of less than $10 \mathrm{~cm}$. As an example of the use of this unique characteristic, modulated rf power, has been used to provide a local increase in $\mathrm{T}_{\mathrm{e}}$. The resultant propagating heat wave can be followed with very high signal to noise ratios using synchronous detection, yielding a direct measurement of energy transport in the electron channel.

Another role for electron cyclotron heating $(\mathrm{ECH})$ and electron cyclotron current drive (ECCD), which is the subject of this paper, is to force a specific time evolution of one of the plasma parameters affected by the absorbed power using a control signal derived from the difference between the desired temporal evolution and the measured evolution. The ultimate example of this would be to require the cw output of a reactor to be, say, $950 \mathrm{MW}$, and to increase the output power of the gyrotron complex until this power level was achieved. A more practical example could be to force the value of $\mathrm{T}_{\mathrm{i}}(0)$ to equal $\mathrm{T}_{\mathrm{e}}(0)$ for the duration of the discharge or to fix $j(\rho=0.5)$ to be held constant at a specified value.

In order to lead toward such advanced applications of ECH and ECCD, the DIII-D plasma control system (PCS) has been configured to provide an analog control signal to the ECH gyrotron system, which can modulate the output power in real time, using feedback. The output power can be varied over a range from $100 \%$ to $10 \%$ of the maximum power available from the system. The flexible signal processing capability of the PCS can digitally filter the response or introduce a phase shift between the error signal and the control signal sent to the ECH system.

\section{EXPERIMENTAL RESULTS}

Feedback control of the output power of the ECH system depends on establishing a relationship between a controllable gyrotron operating parameter and the generated power. In Fig 1, the output power is plotted as a function of the applied high voltage for a high power gyrotron operating at $110 \mathrm{GHz}$. The power can be modulated over $\sim 90 \%$ of the normal range by varying the applied high voltage from its maximum to $\sim 80 \%$ of the maximum. The time response for maximum to minimum output is about $0.1 \mathrm{~ms}$, so rapid response to demand for more or less power can be accommodated. Significantly, the power is a monotonic function of the voltage, so no regions of positive feedback with associated control instability can arise.

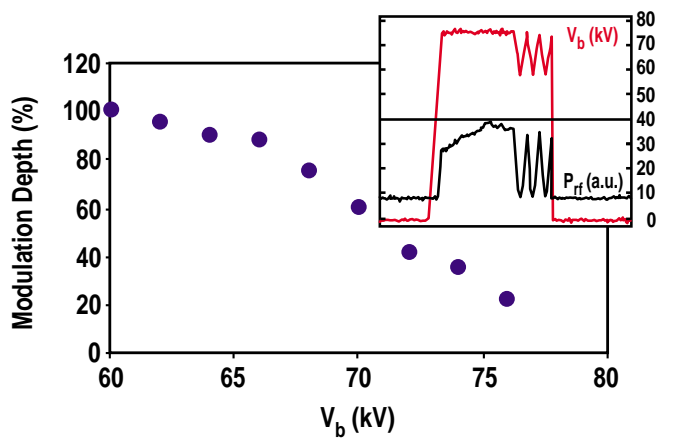

Fig. 1. The output power of a gyrotron at $110 \mathrm{GHz}$ is a monotonic function of the applied high voltage, which permits feedback controlled modulation of the power supply to be used to affect the evolution of the tokamak discharge.

The electron temperature provides a first order response to ECH power. In Fig. 2(a-d), a series of four consecutive tokamak shots demonstrates the feedback control of the electron temperature at a point about halfway between the center and the edge of the plasma. The solid curves are $\mathrm{T}_{\mathrm{e}}(t, \rho=$ $0.5)$ as measured by the ECE system. The dashed curves are the preprogrammed target $\mathrm{T}_{\mathrm{e}}$ evolutions and the hashy short dash curves are the total 


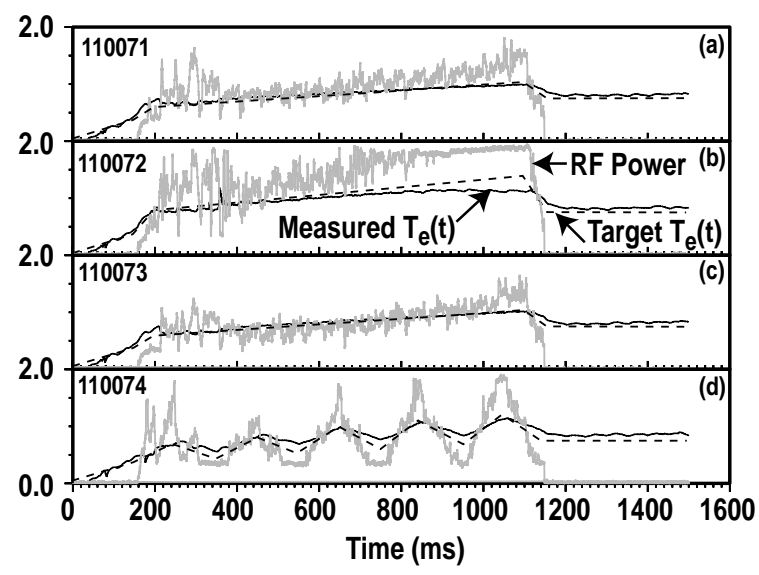

Fig. 2. Measured electron temperature (solid), commanded electron temperature (dashed) and injected $\mathrm{ECH}$ power (grey) for four discharges with different preprogrammed $T_{e}$ evolutions at $\rho=0.5$.

gyrotron output power applied to the plasma. In Fig. 2(a,c) the temperature tracks the desired value fairly accurately, but in Fig. 2(b), after $\sim 800 \mathrm{~ms}$, the $\mathrm{T}_{\mathrm{e}}$ request exceeds the ability of the system even at full output power to achieve the desired temperature. Figure 2(d) is a demonstration of the ability of the system to follow a complex time dependent waveform. Notice that the tracking has good fidelity when the temperature is commanded to increase, but lags when decreases are commanded, because the confinement time then becomes important.

The constraints of "profile consistency," that is, the tendency of the electron temperature profile to, with considerable accuracy, have a generic shape in tokamak discharges, are relaxed when $\mathrm{T}_{\mathrm{e}}$ control is applied. This is shown in Fig. 3, for two discharges, one of which was without ECH, while the second was the discharge of Fig. 2(a) in which ECH was applied to control the temperature evolution. The figure shows the potential for continuous control of the electron temperature profile or of the current density profile if the feedback control is based on a $j(\rho)$ measurement.

Real time control of $\mathrm{T}_{\mathrm{e}}$ provides real time control of the rate of current penetration early in the discharge. In Fig. 4, a series of discharges is shown in which successively higher electron temperatures were commanded in order to reduce the rate of current penetration. As $\mathrm{T}_{\mathrm{e}}$ increased, longer skin times were indicated by the lower central current density measured by the motional Stark effect (MSE) diagnostic. Using a control signal derived directly from the MSE diagnostic should enable the evolution of the current density profile to be controlled.

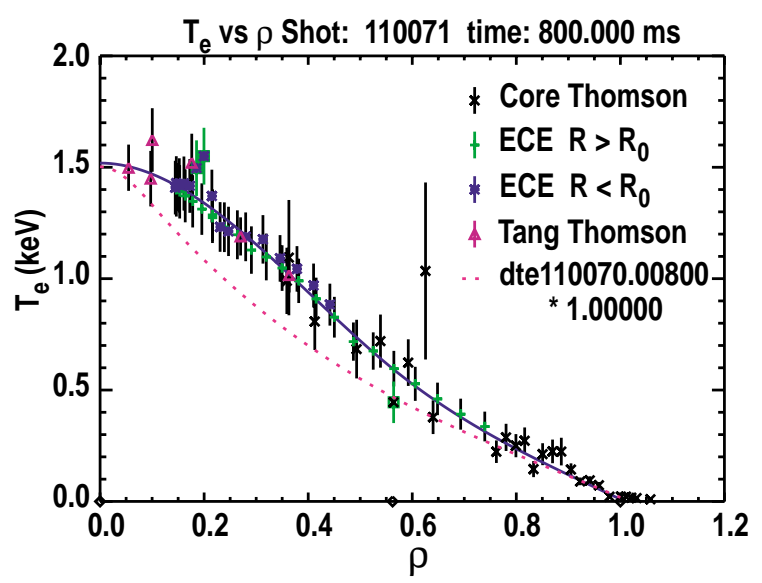

Fig. 3. Electron temperature profiles for the discharge in Fig. 2(a) and for a comparison discharge without ECH taken at $800 \mathrm{~ms}$ showing the control available with the ECH system.

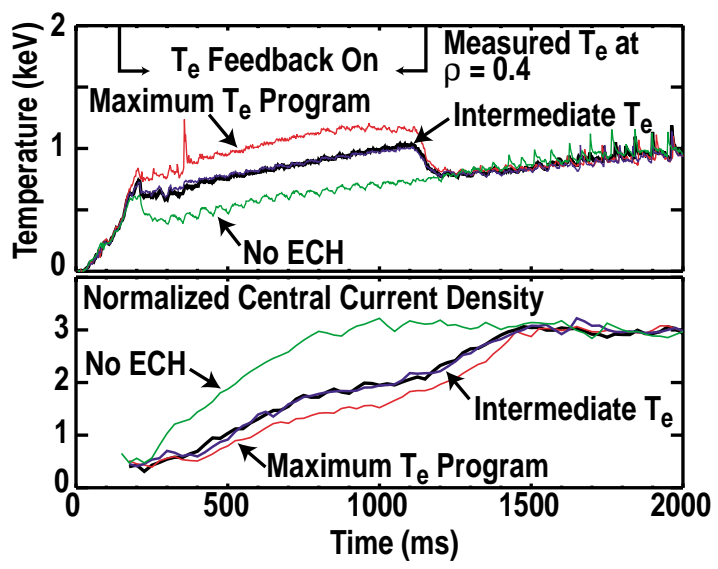

Fig. 4. Commanding higher $\mathrm{T}_{\mathrm{e}}$ inhibits the current penetration early in the discharge and gives control over the $\mathrm{j}(\rho)$ evolution.

\section{CONCLUSION}

Feedback control of the output power of the DIII-D gyrotron complex has been demonstrated using control signals derived from the measurements of the electron temperature. The technique has promise for providing real time control of electron temperature and current density profiles leading to advanced tokamak operation.

\section{ACKNOWLEDGMENT}

This work was supported by the US DOE under Contract Nos. DE-AC03-99ER54463, DE-AC0500OR00033, and DE-AC05-00OR22725. 